\title{
Atenuação da Contaminação de Nitrato em Aqüíferos com Uso de Serragem como Material Reativo: Ensaios de Colunas com Solos
}

\author{
Alexandra Vieira Suhogusoff \\ Instituto de Geociências - Universidade Federal do Rio Grande do Sul \\ suhogusoff@gmail.com \\ Ricardo Hirata \\ Instituto de Geociências - Universidade de São Paulo \\ rhirata@usp.br \\ Luiz Carlos K. M. Ferrari \\ Modcom - Consultoria em Modelagem Numérica \\ luiz.ferrari@modcom.com.br
}

Recebido: 29/07/11 - revisado: 11/12/11 - aceito: 26/07/12

\begin{abstract}
RESUMO
A atenuação de contaminantes em solos e águas pode ser promovida lançando-se mão de meios reativos que, através de reações físicas, químicas ou biológicas, transformem formas nocivas em outras ambientalmente aceitas. É importante que o estudo da eficiência de materiais reativos anteceda à implantação de sistemas de barreiras reativas permeáveis em escala de campo. Esse trabalho mostra os resultados de experimentos de colunas, nos quais testou-se a eficiência da serragem de madeira na degradação de nitrato, um contaminante muito comum em aqüiferos, advindo de sistemas receptores de esgotos sanitários in situ. Três colunas foram montadas em laboratório: uma só com solo da área (C1) e as outras duas com solo da área e $10 \mathrm{~cm}(\mathrm{C2})$ e $20 \mathrm{~cm}(\mathrm{C3})$ de espessura de uma mistura de areia com serragem. A eficiência na remoção de nitrato da solução nas colunas com material reativo foi inicialmente bastante elevada: C3 atuou por $460 \mathrm{~h}$ com mais de $90 \%$ de eficiência e C2, por apenas 35 h. C3 foi em média 2,5 vezes mais eficiente na redução das concentrações de nitrato do que C2.
\end{abstract}

Palavras-chave: Nitrato. Desnitrificação. Material reativo. Serragem. Aqüifero. Ensaios de colunas.

\section{INTRODUÇÃO}

O nitrato $\left(\mathrm{NO}_{3}^{-}\right)$é um composto nitrogenado de alta solubilidade em água e mobilidade, que prevalece em águas subterrâneas altamente oxidantes (FREEZE \& CHERRY, 1979). Sua ingestão em concentrações superiores a $10 \mathrm{mg} / \mathrm{L} \mathrm{N}-\mathrm{NO}_{3}^{-}$(ou 44 $\mathrm{mg} / \mathrm{L} \mathrm{NO}_{3}^{-}$) pode ocasionar doenças como a metahemoglobinemia e alguns tipos de cânceres (WHO, 1999; USEPA, 1995), de forma que essa concentração máxima é definida como padrão de potabilidade (Portaria 2914 do Ministério da Saúde, 2011). Atualmente, devem ser consideradas duas importantes fontes antrópicas de nitrogênio que afetam solos e águas superficiais e subterrâneas: aquela resultante da decomposição de matéria orgânica (advinda de lixões, aterros mal construídos e de dejetos produzi- dos por criações de animais e por sistemas de esgotamento sanitário) e os fertilizantes industriais.

$\mathrm{O}$ atendimento aos padrões de potabilidade torna importante a busca por tecnologias que venham a viabilizar a remoção de nitrato. Existem diversos estudos (ROBERTSON e CHERRY, 1995; ROBERTSON et al., 2000; HIRATA e CESARINO, 2003; MATEJU et al., 1992; VOLOKITA et al. 1996a,b) que mostram a potencialidade do carbono como agente redutor em reações de desnitrificação.

Esse trabalho descreve os ensaios de colunas com solos realizados em laboratório empregando serragem de madeira como material reativo para a degradação de nitrato. Esses experimentos serviram para alicerçar a implementação de uma fossa melhorada com barreiras reativas em um loteamento em Parelheiros (município de São Paulo), cuja comunidade convive com o problema de contamina- 
Atenuação da Contaminação de nitrato em Aqüíferos com Uso de Serragem como Material Reativo:

Ensaios de Colunas com Solos

ção de poços cacimba por sistemas receptores de esgotos sanitários in situ (fossas negras).

\section{Geoquímica da Desnitrificação}

As águas residuárias ricas em material orgânico sofrem diversas reações físicas e químicas em um sistema receptor de esgotos sanitários in situ, mediadas por microorganismos. O efluente então digerido que deixa esse sistema e infiltra no solo é rico em nitrogênio orgânico ou amoniacal, que em contato com oxigênio $\left(\mathrm{O}_{2}\right)$, é nitrificado por microrganismos e, sob a forma de $\mathrm{NO}_{3}^{-}$, pode vir a ingressar nas águas subterrâneas.

O processo reverso à nitrificação, em que ocorre a conversão de formas nitrogenadas oxidadas $\left(\mathrm{NO}_{3}^{-}\right)$para reduzidas $\left(\mathrm{N}_{2}\right.$ ou $\left.\mathrm{N}_{2} \mathrm{O}\right)$ é denominado de desnitrificação (equação 1).

$4 \mathrm{NO}_{3}+5 \mathrm{CH}_{2} \mathrm{O}+4 \mathrm{H}^{+} \Leftrightarrow 2 \mathrm{~N}_{2}+5 \mathrm{CO}_{2}+7 \mathrm{H}_{2} \mathrm{O}$

Para que ocorra a desnitrificação, são necessários alguns fatores (STEVENSON, 1982), tais como: bactérias com capacidade metabólica; doadores de elétrons como compostos de carbono orgânico (bactérias heterotróficas) ou compostos inorgânicos (bactérias autotróficas); condições anaeróbias ou de conteúdo de $\mathrm{O}_{2}$ restrito; óxidos de $\mathrm{N}, \mathrm{NO}_{3}^{-}, \mathrm{NO}_{2}^{-}$, $\mathrm{NO}$ ou $\mathrm{N}_{2} \mathrm{O}$, como aceptores finais de elétrons; e condições favoráveis de $\mathrm{pH}$ e temperatura (diretamente ligadas a performance dos microorganismos).

O material que funcionará como par de óxido-redução com o nitrato é de fundamental importância para o sucesso na reação de desnitrificação desde que os outros fatores sejam atendidos. A matéria orgânica (MO) consiste em uma fonte de carbono a ser oxidada pela atividade microbiológica, mas embora esteja presente na porção mais superficial do solo, ou mesmo em efluentes pouco evoluídos, muitas vezes não é suficiente para atuar na conversão do nitrato advindo de fossas, lixões, ou fertilizantes para formas reduzidas.

A equação 1 simplifica o processo de desnitrificação a partir da matéria orgânica. Observa-se que são necessárias quantidades quase equivalentes de $\mathrm{NO}_{3}^{-}$e de $\mathrm{MO}$ para ocorrer a redução do primeiro para $\mathrm{N}_{2}$. Esse fato leva a outra análise: o teor de $\mathrm{C}$ em uma substância pode afetar a eficiência da redução do $\mathrm{NO}_{3}^{-}$.

O fato das bactérias heterotróficas necessitarem de fontes complexas de $\mathrm{C}$ para seu crescimento e respiração fez com que surgissem diversos estudos com diversas substâncias dessa natureza, tais como acetato, glucose, propanol, butanol, pentanol, ácido fórmico, glicol, melaço e nata do leite (MATEJU et al., 1992).

A celulose constitui outra fonte de carbono, estando presente em todas as plantas. Volokita et al. (1996a) obtiveram desnitrificação quase completa para concentração de $100 \mathrm{mg} / \mathrm{L}$ de nitrato nas condições estabelecidas para os experimentos de coluna utilizando papel jornal como material reativo. Volokita et al. (1996b) também tiveram sucesso na desnitrificação com o emprego de algodão (forma mais pura de celulose encontrada na natureza).

A serragem é amplamente utilizada como material reativo para a reação de desnitrificação (ROBERTSON e CHERRY, 1995; ROBERTSON e AANDERSON, 1999; SCHIPPER e VOJVODICVULKOVIC, 1998, 2001; ROBERTSON et al., 2000; HIRATA e CESARINO, 2003). Esses estudos fundamentaram-se na operação de sistemas de barreiras reativas como forma de interceptar plumas contaminantes de nitrato e reportaram a taxas de degradação desse contaminante variando de 60 a $100 \%$. Vogan (1993) estudou o papel da serragem, entre outros materiais, em experimentos de coluna e também constatou significativa desnitrificação.

\section{MATERIAIS E MÉTODOS}

A coluna correspondeu a um cilindro de acrílico (plexiglass) de $5 \mathrm{~cm}$ de diâmetro e $40 \mathrm{~cm}$ de comprimento, em cujas extremidades adaptam-se discos (endplates), também de plexiglass, ranhurados concêntrica e radialmente e presos à coluna por parafusos; sob a depressão das ranhuras nos endplates são ajustados um filtro grosso e um fino (este em contato direto com o solo). Em cada um dos endplates, há duas conexões para inserção de duas mangueiras de Teflon por onde percolam os fluidos (Figura 1).

Os solos usados nas colunas foram coletados a uma profundidade média de $3 \mathrm{~m}$ (próximo ao nível d'água) de alguns pontos da área de estudos, o loteamento Jardim Santo Antônio (Parelheiros, distrito a sul do município de São Paulo). Os solos coletados corresponderam basicamente ao regolito de rochas gnáissicas a xistosas do Complexo Embu (Grupo Açungui), com a presença de quartzo, feldspatos, muscovita, biotita e anfibólio em sua mineralogia. Os solos apresentaram coloração predominantemente avermelhada com granulação arenosiltosa. 
Três colunas foram preparadas para o experimento: a Coluna 1 (C1) foi montada apenas com solo da região, a Coluna 2 (C2) com $10 \mathrm{~cm}$ de material reativo inserido no meio do solo e a Coluna 3 (C3) com $20 \mathrm{~cm}$ de material reativo no meio do solo (Figura 1).

Os solos foram secos em estufa a $60^{\circ} \mathrm{C}$ por $48 \mathrm{~h}$ e depois desagregados, passando por uma peneira de 9 mesh. O solo foi então empilhado gradualmente $\left(\sim 200 \mathrm{~cm}^{3}\right.$ de cada vez) com o auxílio de um pilão de aço. Para a inserção do material reativo nos intervalos de 10 e $20 \mathrm{~cm}$ de C2 e C3, respectivamente, foi preparada uma mistura de serragem de cedrinho (espécie Erisma uncinatum Warm., família Vochysiaceae) e areia quartzosa média, de forma a corresponder a um foc (fração de carbono orgânico) de $2,5 \%$, valor baseado em experimentos semelhantes desenvolvidos por Vogan (1993). Os teores de carbono para o solo e a serragem foram obtidos por análise elementar (\%CHN) através do laboratório Central Analítica (Instituto de Química -USP), utilizando-se um Perkin-Elmer CHN2400. As amostras inseridas em cápsulas de alumínio são submetidas à combustão a $1000^{\circ} \mathrm{C}$, produzindo-se $\mathrm{CO}_{2}, \mathrm{H}_{2} \mathrm{O}$ e $\mathrm{NO}_{2}$ que são separados na zona cromatográfica e depois medidos por detectores de condutividade térmica. Os teores de carbono orgânico corresponderam a $0,20 \%$ para solo e $45,18 \%$ para a serragem.

As colunas foram pesadas de quatro formas diferentes: secas; preenchidas d'água; preenchidas com solo seco; e preenchidas com solo saturado. $\mathrm{O}$ objetivo das pesagens foi o de obter parâmetros físicos tais como densidade do material e volume de poros (VP) da coluna.

Antes da saturação das colunas preenchidas com solo, estas foram submetidas a uma injeção de $\mathrm{CO}_{2}$ por $24 \mathrm{~h}$ para que este gás substituísse o ar dos poros. Essa estratégia é usada para aumentar as chances de se obter uma saturação por água completa, já que o $\mathrm{CO}_{2}$ é mais facilmente dissolvido em água. $\mathrm{O}$ escape de gases das colunas foi observado em suas outras extremidades pelo borbulhamento em um becker preenchido de água.

A saturação das colunas com água destilada foi realizada de baixo para cima através de uma bomba peristáltica de baixa vazão da marca Watson Marlow modelo 401U/DM3.

Após a saturação das colunas, procedeu-se com a injeção da solução constituída de água destilada com nitrato e brometo dissolvidos. A vazão da bomba foi ajustada para a média de 1 VP (VP de C1, C2 e C3 respectivamente de 282, 250 e $338 \mathrm{~mL}$ ) por dia para as 3 colunas, correspondendo a aproximadamente $0,2 \mathrm{~mL} / \mathrm{min}$.
A primeira solução de influente foi introduzida nas três colunas com uma concentração de $\mathrm{NO}_{3} \cong 65 \mathrm{mg} / \mathrm{L}$ e de $\mathrm{Br} \cong 59 \mathrm{mg} / \mathrm{L}$, e a um $\mathrm{pH}$ de aproximadamente 7 e temperatura em torno de $25^{\circ} \mathrm{C}$, condições essas satisfatórias para um bom desempenho das bactérias desnitrificantes (MATEJU et $a l ., 1992)$.

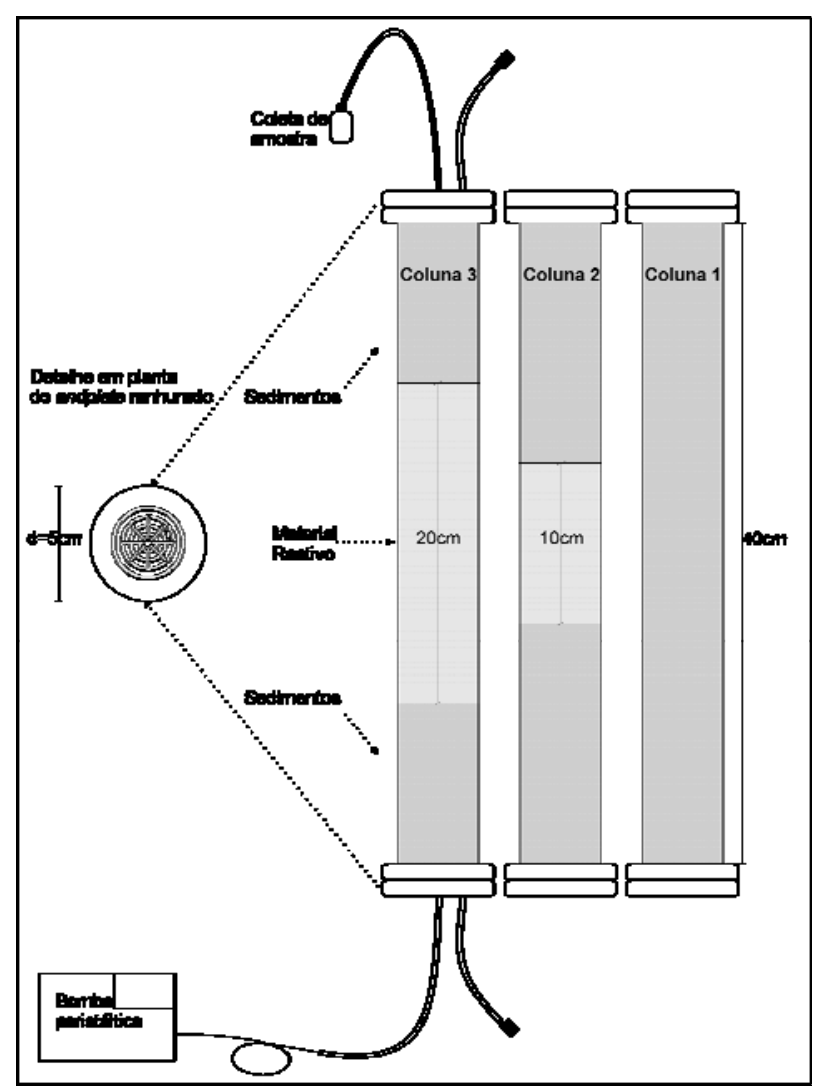

Figura 1 - Esquema das colunas com solo

Essa solução foi então injetada nas colunas previamente saturadas com água destilada. As amostragens iniciaram-se $0,5 \mathrm{VP}$ após essa injeção, com coleta sistemática de $3 \mathrm{em} 3 \mathrm{~h}$ para levantamento da curva concentração como função do tempo do traçador $\mathrm{Br}^{-}$, com acúmulo de amostra de pelo menos 2 h. A solução do influente apresentou um volume de $822 \mathrm{~mL}$, que, distribuído para as 3 colunas, correspondeu a $274 \mathrm{~mL}$ para cada uma delas, isto é, aproximadamente 1 VP. Dessa forma, a solução inicial demorou $23 \mathrm{~h}$ para ser completamente injetada (após o que outras soluções contendo só nitrato foram injetadas). A frente dos solutos $\mathrm{Br}^{-}{\mathrm{e} \mathrm{NO}_{3}}^{-}$começou a chegar no ponto de amostragem findo esse período. A amostragem sistemática para captura da curva do traçador durou ao todo $60 \mathrm{~h}$ (ou 2,5 VP), com a co- 
leta de 60 amostras (20 para cada coluna) com 20 $\mathrm{mL}$ em média de volume. Foram coletadas 12 amostras ao longo do experimento para análise de Carbono Orgânico Dissolvido (COD).

Após o pulso de $\mathrm{Br}^{-}$(injetado com o objetivo de se obter parâmetros hidráulicos da zona saturada criada na coluna, como velocidade de fluxo e dispersão), continuou-se com a injeção de $\mathrm{NO}_{3}^{-}$à concentração aproximada de $65 \mathrm{mg} / \mathrm{L}(\mathrm{pH} \cong 7,0$ e $\mathrm{T} \cong$ $25^{\circ} \mathrm{C}$ ) com o propósito de se acompanhar a evolução de sua degradação por um tempo mais longo. $\mathrm{O}$ experimento total teve uma duração de 2140 h (cerca de 3 meses), totalizando 108 amostras coletadas (36 para cada coluna).

As amostras para análise dos ânions $\mathrm{NO}_{3}{ }^{-} \mathrm{e}$ $\mathrm{Br}^{-}$foram acondicionadas em frascos de vidro âmbar, resfriadas e processadas em um cromatógrafo de troca iônica Dionex 2010i pelo Centro de Pesquisas de Águas Subterrâneas (CEPAS) do Instituto de Geociências da USP. O cromatógrafo utiliza como eluente uma solução de carbonato/bicarbonato de sódio e um sistema composto por coluna separadora de troca aniônica IonPac AS4A-SC, coluna supressora química ASRS, detector de condutância elétrica e registrador de dados.

As amostras para teor de COD foram analisadas pelo método de combustão a alta temperatura por um Shimadzu TOC5000 pelo Laboratório de Saneamento da Escola de Engenharia de São Carlos (USP). A amostra é primeiramente atacada com $\mathrm{HCl}$ $2 \mathrm{~N}$ para eliminação de carbono inorgânico e depois submetida à oxidação catalítica para geração de $\mathrm{CO}_{2}$ detectado por infravermelho não dispersivo.

Os modelamentos numéricos para obtenção dos parâmetros de transporte das três colunas foram realizados pelo programa STANMOD CXTFIT 2.2 (TORIDE et al., 1999). Esse programa, baseando-se em uma solução analítica da equação de advecção e dispersão, permite que se ajustem os parâmetros de transporte de soluto, de forma que a diferença entre os valores de concentração preconizados pela solução analítica e os das concentrações observadas em experimentos de injeção de traçador em laboratório ou em campo seja mínima.

\section{RESULTADOS E DISCUSSÃO}

\section{Curvas Concentração como função da Quantidade \\ de Volumes de Poros}

As curvas de brometo $\left(\mathrm{C} / \mathrm{C}_{0}\right)$ como função de VP para as três colunas são apresentadas nas Figuras 2 a 4 .
A injeção de $24 \mathrm{~h}$ de brometo em cada coluna gerou curvas aproximadamente gaussianas que se estenderam a até $80 \mathrm{~h}$ ou aproximadamente 3,5 VP. O maior espalhamento da curva em C1 (branco) ocorre devido à maior dispersão do soluto (traçador) para esse caso; o preenchimento presente na espessura com serragem de C2 e C3 diminui a dispersão, uma vez que os tamanhos dos poros e os trajetos intraporos mais uniformes propiciam caminhos menos divergentes para o fluxo d'água.

Os parâmetros de transporte para as três colunas foram obtidos pelo programa CXTFIT.

Os valores calibrados para fluxo e dispersividade, considerando o brometo como traçador conservativo e sem retardação, são apresentados na Tabela 1 .

As velocidades calculadas mostram que o tempo de residência da solução para C1, C2 e C3 correspondem a $24,4,23,5$ e $27,4 \mathrm{~h}$, respectivamente. Os tempos de residência da solução no material reativo, calculados através das velocidades acima e das espessuras da mistura areia-serragem de cada coluna, foram de aproximadamente $5,9 \mathrm{~h}$ para C2 e 13,3 h para C3.

Considerando uma injeção contínua de nitrato no período ensaiado, as curvas para a C1 indicam que o nitrato se comporta como o brometo: em torno de $10 \mathrm{~h}(0,43 \mathrm{VP})$, esse ânion atinge o fim da coluna com concentrações máximas, similares àquelas de entrada $(\sim 65 \mathrm{mg} / \mathrm{L})$. Para o caso de C2 (10 $\mathrm{cm}$ de material reativo), o nitrato começa a aparecer após $20 \mathrm{~h}$ (1 VP), alcançando concentrações da ordem de $0,90 \mathrm{C}_{0}$ após $591 \mathrm{~h}(28 \mathrm{VP})$. Para a C3 $(20 \mathrm{~cm}$ de material reativo), as concentrações desse ânion começam a ser detectadas somente após 364,5 h (13 $\mathrm{VP})$, atingindo concentrações de cerca de $0,90 \mathrm{C}_{0}$ após 741 h (26 VP), cabendo ressaltar que os valores de concentrações finais para essa coluna não atingiram aquele da injeção.

Tabela 1 - Valores calibrados para brometo

\begin{tabular}{|l|l|l|l|}
\hline Parâmetros & C1 & C2 & C3 \\
\hline$v(\mathrm{~cm} / \mathrm{h})$ & 1,643 & 1,698 & 1,464 \\
\hline$D(\mathrm{~cm})$ & 4,173 & 1,659 & 0,592 \\
\hline
\end{tabular}

\section{Eficiência da desnitrificação}

A Figura 5 mostra a eficiência na redução de concentrações de nitrato de cada uma das colunas com serragem como função do tempo. Como base de comparação, foram obtidos valores de concentração de nitrato para colunas hipotéticas (C2 e 


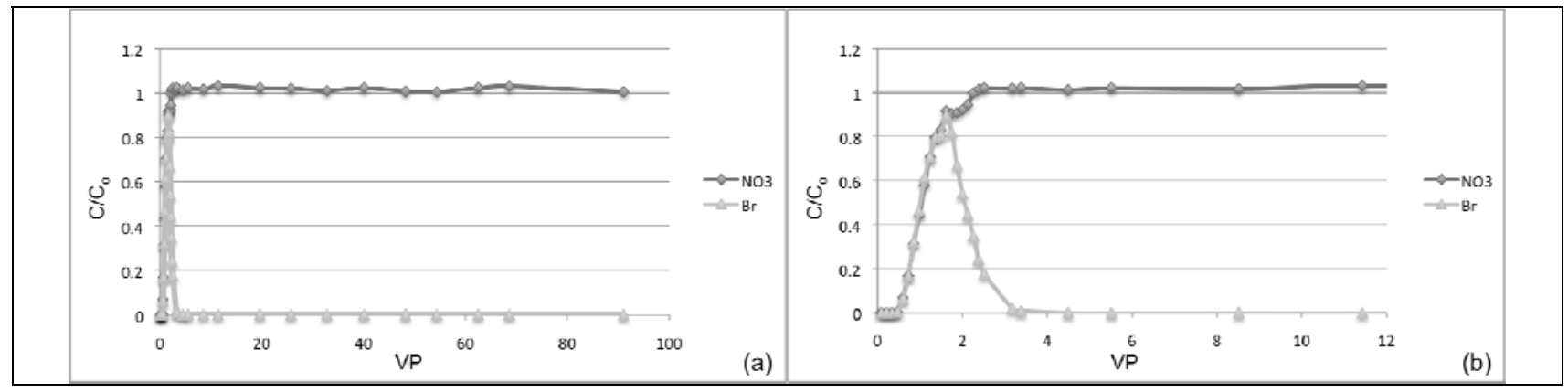

Figura 2 - Curvas de nitrato e brometo $\left(C / C_{0} \times\right.$ VP) para a Coluna 1: (a) intervalo de 0-100 VP e (b) intervalo de 0-12 VP

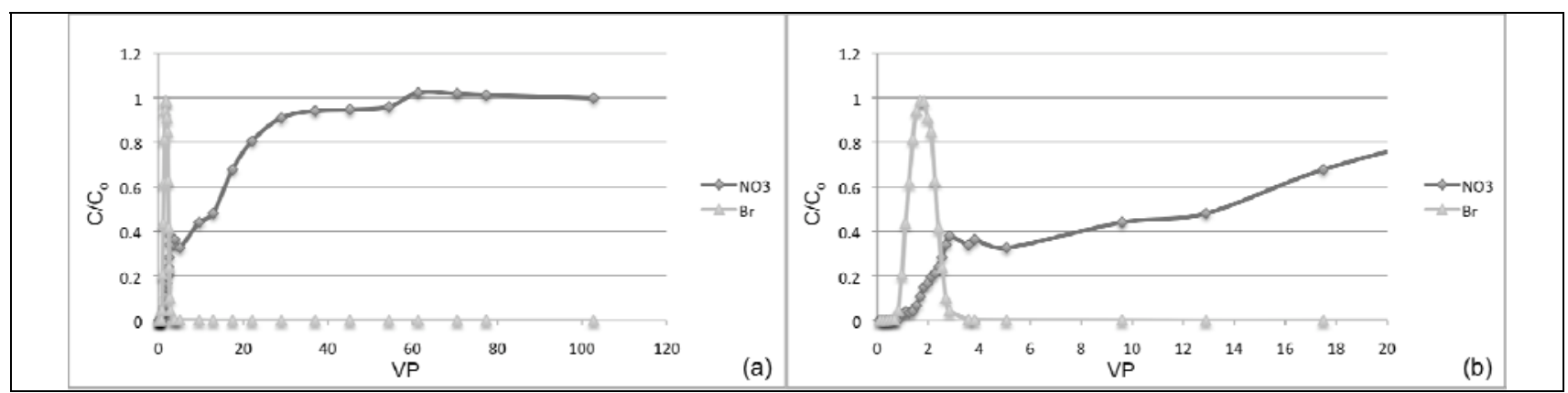

Figura 3 - Curvas de nitrato e brometo $\left(\mathrm{C} / \mathrm{C}_{0} \times \mathrm{VP}\right)$ para a Coluna 2: (a) intervalo de 0-100 VP e (b) intervalo de 0-20 VP

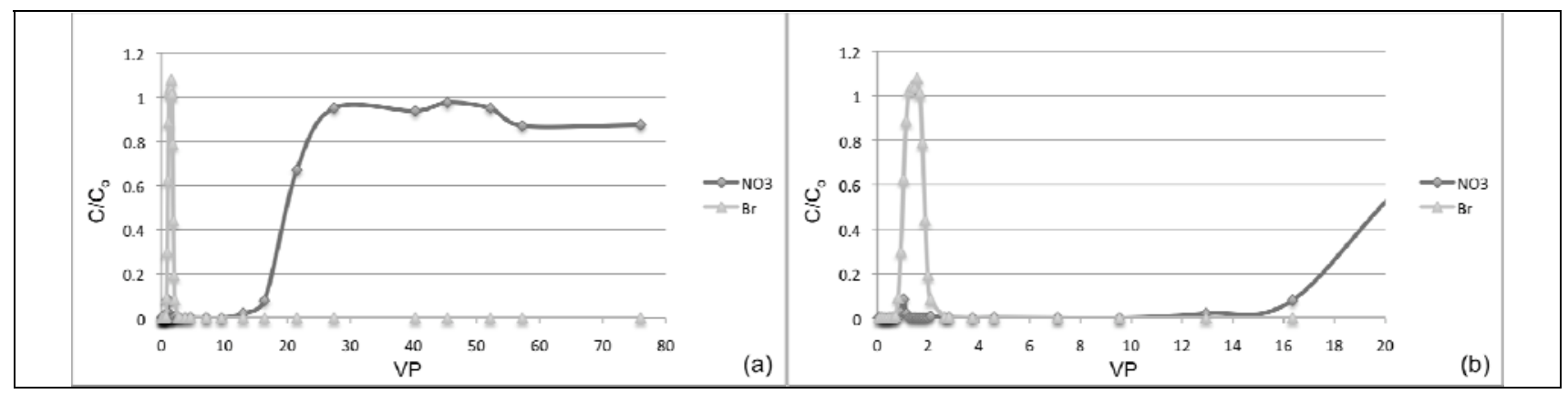

Figura 4 - Curvas de nitrato e brometo $\left(C / C_{0} \times\right.$ VP) para a Coluna 3: (a) intervalo de 0-80 VP e (b) intervalo de 0-20 VP

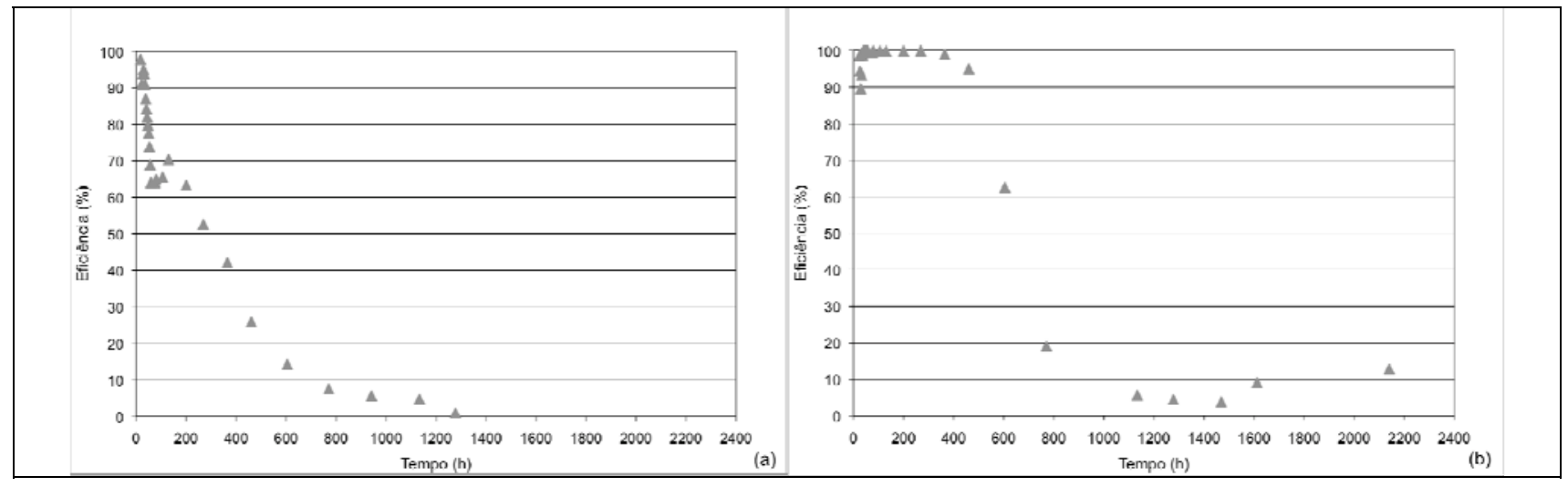

Figura 5 - Eficiência, em \%, como função do tempo (h) para (a) Coluna 2 e (b) Coluna 3 
C3’) sem a ocorrência de degradação através do programa CXTFIT. Tomando-se como exemplo C2, valores de dispersão e velocidade de brometo anteriormente obtidos (Tabela 1) foram empregados no cálculo de concentrações de nitrato para C2', fixando-se uma taxa de degradação nula. O coeficiente de retardação atribuído correspondeu a 1, uma vez que as curvas de nitrato com degradação anteriormente levantadas não apresentaram retardação. A eficiência de $\mathrm{C} 2, \mathrm{E}_{\mathrm{C} 2}(\mathrm{t})$, expressa em porcentagem, foi calculada segundo a equação:

$$
E_{C 2}(t)=100 \cdot \frac{I_{C 2^{\prime}}(t)-I_{C 2}(t)}{I_{C 2^{\prime}}(t)}
$$

na qual $\mathrm{I}_{\mathrm{Ci}}(\mathrm{t})$ é a integral, calculada através do método do trapézio, da curva $\mathrm{C} / \mathrm{C}_{0}$ de Nitrato como função do tempo para a coluna i entre o tempo 0 e o tempo t. A taxa de degradação de $\mathrm{C} 2, \lambda_{\mathrm{C} 2}(\mathrm{t})$, que regula o decaimento exponencial provocado pela ação da serragem presente em C2 na degradação do nitrato como função do tempo foi calculada segundo a equação:

$$
\lambda_{\mathrm{C} 2}(\mathrm{t})=\frac{1}{\mathrm{t}} \cdot \ln \left(\frac{\mathrm{I}_{\mathrm{C} 2^{\prime}}(\mathrm{t})}{\mathrm{I}_{\mathrm{C} 2}(\mathrm{t})}\right)
$$

A eficiência e a taxa de degradação de C3, $\mathrm{E}_{\mathrm{C} 3}(\mathrm{t})$ e $\lambda_{\mathrm{C} 3}(\mathrm{t})$, foram calculadas de modo análogo.

Observa-se que a curva de eficiência de C2 apresenta uma linha de tendência exponencial, enquanto que a curva de C3 tenta esboçar o mesmo padrão, contudo com a definição de dois patamares: um entre 0 e $500 \mathrm{~h}$ e outro entre 1100 e $1700 \mathrm{~h}$ (Figura 5). Em C2, observa-se também que a eficiência sofre uma redução muito mais brusca que C3 nas primeiras horas do experimento.

Em ambas as colunas, a eficiência na remoção de nitrato da solução é inicialmente bastante elevada: C2 chega a atingir uma eficiência de 97,8\% e C3, de 99,95\%. Em quase 770 h de experimento, tal eficiência reduz-se a valores da ordem de 7,5\% para C2 e 19\% para C3, sendo que o tempo em que C3 atua com mais de $90 \%$ de eficiência $(\sim 460 \mathrm{~h})$ é consideravelmente superior ao tempo em que C2 atua com mesma porcentagem ( $235 \mathrm{~h}$ ) (Figura 5$)$. A comparação entre as eficiências das duas colunas indica que, na média, C3 é cerca de 2,5 vezes mais eficiente na redução das concentrações de nitrato que C2, considerando-se todo o tempo de experimento. Essa medida é aproximada, já que essa comparação é realizada em termos de horas e não em
Volume de Poros, uma vez que cada coluna possui seu próprio VP.

Na Figura 6, é possível observar como ocorre a retomada da massa de nitrato que deixa a coluna ao longo do tempo (C2 e C3), em comparação às concentrações ideais de nitrato sem degradação (C2' e C3'). Trata-se de uma outra forma de mostrar como a degradação em C3 atua por mais tempo que em C2.

A comparação das curvas de taxa de degradação mostra que $\lambda$ relativo à $\mathrm{C} 3$ é em média 1,6 vezes superior que o relacionado à C2 (Figura 7). Em termos de meia vida, considerando-se o intervalo entre 23 e $47 \mathrm{~h}$, a meia vida do nitrato de C2 aumenta de 6,7 para 15,5 h, ao passo que a de C3 parte de 7,9 e atinge apenas 8,5 h. Em $940 \mathrm{~h}$ para C2 e 1470 h para C3, a meia vida aumenta em ambas para aproximadamente $1900 \mathrm{~h}$.

As massas de nitrato que atravessaram as colunas após todo o experimento corresponderam a 2,15 g para C1, 1,85 g para C2 e 1,45 g para C3. A massa de carbono contida nas misturas reativas de C2 e C3 por meio da serragem corresponderam a 6,3 g e 12 g, respectivamente. A integração das massas desnitrificadas ao longo do tempo experimentado de C2 e C3 resultaram nos valores de 265,55 mg $(12,6 \%$ da massa injetada em C2) e 669,29 mg (31,7\% da massa injetada em C3), respectiva-mente. A integração da tendência das massas de COD ao longo do tempo mostra que houve passagem de aproximadamente $1 \mathrm{~g}$ de COD para cada uma das colunas. Esse $1 \mathrm{~g}$ de COD não utilizado na desnitrificação indica que o tempo de residência da solução nas colunas não são suficientes para interação máxima de aproveita-mento entre bactérias e carbono/nitrato, ou seja, o fluxo de nitrato é superior à capacidade de carbono ser liberado da serragem e assimilado em solução. O fato da eficiência de C3 ser maior do que C2 e a massa desnitrificada de C3 ser 2,5 vezes superior que C2 também sugere que não só a quantidade de carbono, mas a espessura do material reativo, e portanto, o tempo de residência, têm influência na taxa de desnitrificação.

A diferença expressiva entre o carbono contabilizado na serragem e o carbono consumido na desnitrificação somado ao COD (excesso) pode ser explicada pela disponibilidade de carbono livre na estrutura molecular da serragem. No emprego de materiais em barreiras reativas, torna-se desejável que a real taxa de solubilização de carbono seja conhecida a fim de não se utilizar essa tecnologia a uma capacidade inferior da esperada somente por estequiometria simples de massas. 


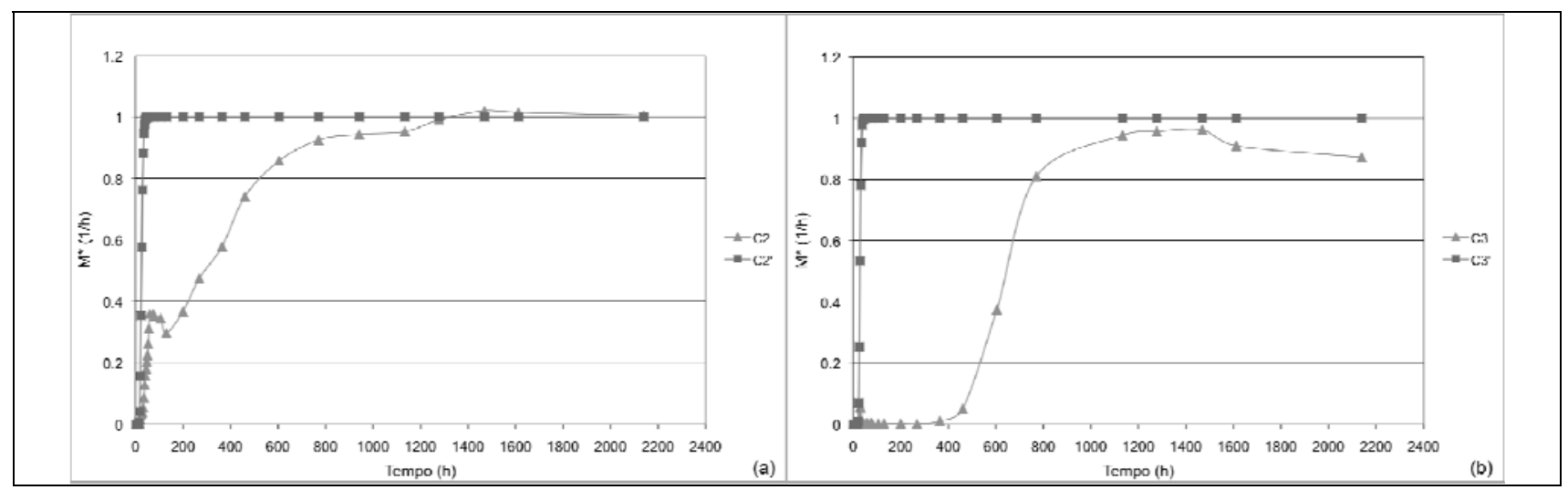

Figura 6 - Massa de nitrato que atravessa a coluna por hora com degradação e sem degradação para (a) Coluna 2 e (b) Coluna 3. $M^{*}$ : massa normalizada por unidade de tempo (h)

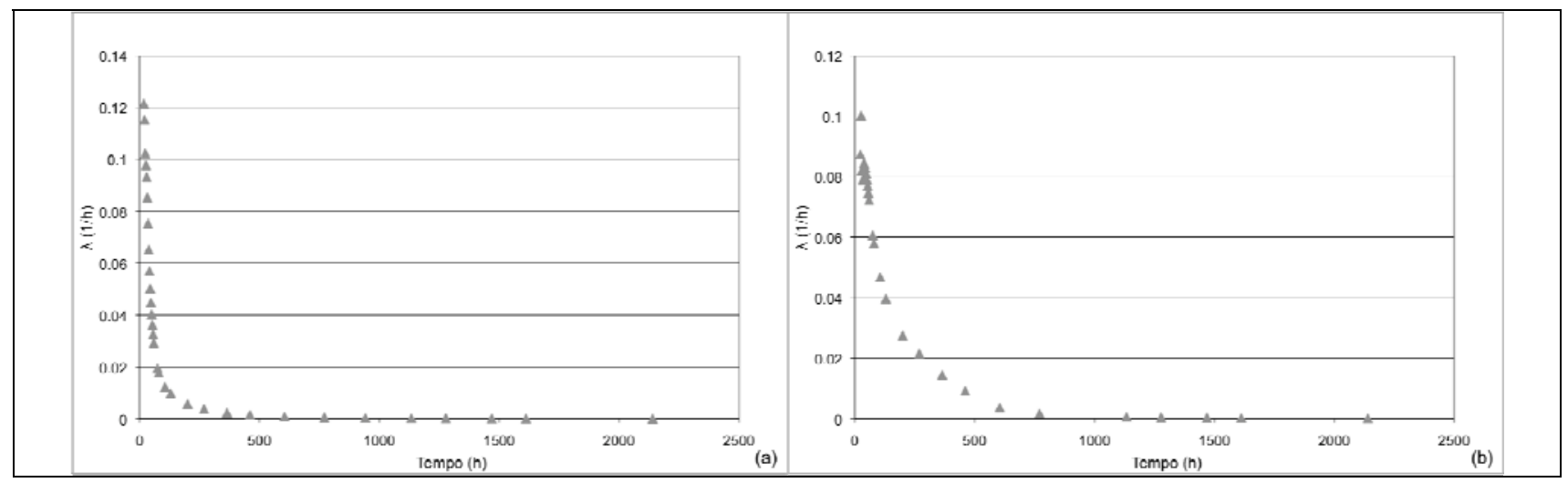

Figura 7 - Taxa de degradação (1/h) como função do tempo (h) para (a) Coluna 2 e (b) Coluna 3

\section{CONCLUSÕES}

Nas duas colunas com materiais reativos, a eficiência na remoção de nitrato da solução é inicialmente bastante elevada: em C3, o tempo em que a serragem atua com mais de $90 \%$ de eficiência é de aproximadamente $460 \mathrm{~h}$, ao passo que em C2, esse tempo é bem menor, de apenas 35 h. C3 é em média 2,5 vezes mais eficiente na redução das concentrações de nitrato que C2. As porcentagens das massas totais de nitrato que passaram por C2 e C3 foram respectivamente de $12,6 \%$ e $31,7 \%$. A quantidade de nitrato degradada obtida não é condizente com o que se esperava pela estequiometria $\mathrm{C}_{2} \mathrm{NO}_{3}{ }^{-}$, o que mostra a observância de dois fatores: tempo de residência adequado da solução contaminada no material reativo e pronta disponibilidade de carbono na fase dissolvida.

O emprego de serragem como material reativo mostrou-se ser eficiente na atenuação de nitrato, de forma que esse material foi empregado na implantação de fossas melhoradas com barreiras reativas na área de estudos.

\section{AGRADECIMENTOS}

Os autores são gratos à Fundação de Amparo e à Pesquisa do Estado de São Paulo pelo auxílio concedido e ao Dr. Jesse Stimson pela assistência na montagem das primeiras colunas e pela obtenção dos materiais envolvidos.

\section{REFERÊNCIAS}

FREEZE, R.; CHERRY, J. Groundwater. New Jersey: Prentice-Hall, 1979. 604p. 
Atenuação da Contaminação de nitrato em Aqüíferos com Uso de Serragem como Material Reativo:

Ensaios de Colunas com Solos

HIRATA, R.; CESARINO, A. Barreiras reativas: Uma tecnologia de baixo custo para aqüíferos contaminados. Meio Ambiente Industrial, 2003. p. 109-113.

MATEJU, V.; CIZINSKA, S.; KREJCI, J.; JANOCK, T. Biological water denitrification - a review. Enzyme Microb. Technology, v. 14, p. 170-183, 1992.

MINISTÉRIO DA SAÚDE. Procedimentos de controle $e$ de vigilância da qualidade da água para consumo humano e seu padrão de potabilidade. Portaria MS 2914 de $12 / 12 / 2011$.

ROBERTSON, W. D.; ANDERSON, M. R. Nitrogen removal from landfill leachate using na infiltration bed coupled with a denitrification barrier. Groundwater monitoring Eo remediation, Fall, 1999, p.73-80.

ROBERTSON, W.D.; BLOWES, D. W.; PTACEK, C. J. \& CHERRY, J.A. Long-term perfomance of in situ reactive barriers for nitrate remediation. Groundwater, v. 38, n. 5, p. 689-695, 2000.

ROBERTSON, W. D. \& CHERRY, J. A. In situ denitrification of septic-system nitrate using reactive porous media barriers: Field trials. Groundwater, v. 33, n. 1, p. 99-111, 1995.

SCHIPPER, L.; VOJVODIC-VUKOVIC, M. Five years of nitrate removal, denitrification and carbon dynamics in denitrification wall. Water Research, v. 35, n. 14, p. 3473-3477, 2001.

SCHIPPER, L.; VOJVODIC-VUKOVIC, M. Nitrate removal from groundwater using a denitrification wall amended with sawdust: field trial. Journal of Environmental Quality, v. 27, n. 3, p. 664-668, 1998.

STEVENSON, F. J. (editor). Nitrogen in agricultural soils. Serie Agronomy, n 22. Madison, Wisconsin (USA), 1982. 940p.

SUHOGUSOFF, A. V.; STIMSON, J.; HIRATA, R.; BLOWES, D.; PTACEK, C.; ROBERTSON, W.; ARAVENA, R.; FERRARI, L. C. Implementation of an alternative cesspit with the use of sawdust as permeable reactive barrier for nitrate removal: pilot study in Parelheiros. Sao Paulo, Brazil, 2011. Em preparação.

TORIDE, N., F. J.; LEIJ, VAN GENUCHTEN M. TH. The CXTFIT code for estimating transport parameters from laboratory or field tracer experiments. Version 2.1. Research Report no 137, U.S. Salinity Laboratory, USDA, ARS, Riverside, CA, 1999. 121 p.
VOGAN, J. L. The use of emplaced denitrifying layers to promote nitrate removal from septic effluent. 1993. 232f. Dissertação (Mestrado) - Department Earth Sciences, University of Waterloo. Ontario, 1993.

VOLOKITA, M.; BELKIN, S.; ABELIOVICH, A.; SOARES, M. I. M. Biological denitrification of drinking water using newspapers. Water Research, v. 30, n. 4, p. 965-972, 1996a.

VOLOKITA, M.; ABELIOVICH, A.; SOARES, M. I. M. Denitrification of groundwater using cotton as energy source. Water Science and Technology, v. 34, n. 1-2, p. 379-385, 1996b.

WHO. World Health Organization. "Environmental health information", 1999. Disponível em: URL: http:/ / www.who.int. Acesso em 2004.

USEPA. United States Environmental Protection Agency. "Drinking water regulations and health advisores", 1995. Disponível em: URL: http:// www.epa.gov. Acesso em 2004

\section{Attenuation of Nitrate Contamination in Aquifers Using Sawdust as Reactive Material: Column Ex- periments with Soils}

\section{ABSTRACT}

The attenuation of contaminants in soil and water can be promoted using reactive media that, through physical, chemical or biological reactions, transform harmful forms into environmentally accepted ones. It is important that the study of reactive materials efficiency precede the implementation of permeable reactive barriers at field scale. This paper shows the results of column experiments in which the efficiency of sawdust was tested in the degradation of nitrate, a very common contaminant in aquifers, from in situ sanitation systems. Three columns were set up: one with sediments from the area (C1) and the other two with sediments from the area and $10 \mathrm{~cm}(\mathrm{C2})$ and $20 \mathrm{~cm}$ (C3) thickness of sand mixed with sawdust. The removal efficiency of nitrate solution in the columns with reactive material was initially quite high: C3 worked for $460 h$ with an efficiency above $90 \%$ and C2, for only 35 h. C3 was on average 2.5 times more efficient in reducing nitrate concentrations than C2.

Key-words: nitrate, denitrification, reactive material, sawdust, aquifer, columns experiments 